\title{
THE GEOMETRY OF BLUNDON'S CONFIGURATION
}

\section{DORIN ANDriCA, CĂTĂLIN BARBU AND LAURIAN IOAN PIŞCORAN}

Abstract. Denote by $\mathscr{T}(R, r)$ the family of triangles inscribed in the circle of center $O$ with the radius $R$ and circumscribed to the circle of center $I$ with the radius $r$. This defines the Blundon's configuration. The family $\mathscr{T}(R, r)$ contains only two isosceles triangles $A_{\min } B_{\min } C_{\min }$ and $A_{\max } B_{\max } C_{\max }$, which are extremal for Blundon's inequalites (1). Some properties of Blundon's configuration are given Section 2. Applications are presented in the last section where a strong version of Blundon's inequalites is obtained (Theorem 7).

Mathematics subject classification (2010): 26D05, 26D15, 51N35.

Keywords and phrases: Strong version of Blundon's inequalities, law of cosines, circumcenter, incenter, Nagel point of a triangle, Blundon's configuration.

\section{REFERENCES}

[1] T. Andreescu, D. Andrica, Complex Number from A to..Z, Second Edition, Birkhäuser, 2014.

[2] D. AndricA, C. BArbu, A geometric proof of Blundon's Inequalities, Math. Inequal. Appl., 15 2(2012), 361-370.

[3] D. Andrica, C. Barbu, N. Minculete, A geometric way to generate Blundon type inequalities, Acta Universitatis Apulensis, 31 (2012), 93-106.

[4] D. ANDRICA, C. BARBU, L. PIŞCORAN, The geometric proof to a sharp version of Blundon's inequalities, J. Mathematical Inequalities, 10 4(2016), 1037-1043.

[5] D. Andrica, K. L. Nguyen, A note on the Nagel and Gergonne points, Creative Math.and Inf., 17 (2008), 127-136.

[6] T. BIRSAN, Bounds for elements of a triangle expressed by $R, r$, and $s$, Forum Geometricorum, 15 (2015), 99-103.

[7] W. J. Blundon, Inequalities associated with the triangle, Canad. Math. Bull., 8 (1965), 615-626.

[8] G. Dospinescu, M. LAscu, C. POHOAŢĂ, M. Tetiva, An elementary proof of Blundon's inequality, J. Inequal. Pure Appl. Math., 9 (2008), A 100.

[9] D. S. Mitrinović, J. E. PeČArić, V. Volenec, Recent Advances in Geometric Inequalities, Kluwer Acad. Publ., Amsterdam, 1989.

[10] C. P. Niculescu, A new look at Newton's inequality, J. Inequal. Pure Appl. Math., 1 (2000), A 17.

[11] C. P. NiculesCU, On the algebraic character of Blundon's inequality, Inequality Theory and Applications, Edited by Y. J. Cho, S. S. Dragomir, J. Kim, Vol. 3, Nova Science Publishers, New York, 2003. 139-144.

[12] M. RADIC, Extreme areas of triangles in Poncelet's closure theorem, Forum Geometricorum, 4 (2004), $23-26$.

[13] R. A. SATNOIAnu, General power inequalities between the sides and the circumscribed and inscribed radii related to the fundamental triangle inequality, Math. Inequal. Appl., 54 (2002), 745-751.

[14] S-H. WU, Y-M. CHU, Geometric interpretation of Blundon's inequality and Ciamberlini's inequality, Journal of Inequalities and Applications, (2014), 2014: 381.

[15] S. WU, A sharpened version of the fundamental triangle inequality, Math. Inequalities Appl., 11 3(2008), 477-482. 